\title{
Increased expression of selectins in kidneys of patients with diabetic nephropathy
}

\author{
K. Hirata, K. Shikata, M. Matsuda, K. Akiyama, H. Sugimoto, M. Kushiro, H. Makino \\ Department of Medicine III, Okayama University Medical School, Okayama, Japan
}

\begin{abstract}
Summary In diabetic nephropathy leukocytes, mainly composed of monocytes/macrophages, which accumulate in the glomeruli and the interstitium, play an important part in the progression of glomerulosclerosis. The infiltration of leukocytes into inflammatory tissues or atherosclerotic lesions is mediated by adhesion molecules, which are expressed on the vascular endothelial cells, although little is known about the mechanism of leukocyte infiltration into diabetic renal tissues. P- and E-selectin are leukocyte adhesion molecules, which are expressed on the vascular endothelial cells and promote the adhesion of leukocytes to the endothelium. We investigated the expression of Pand E-selectin in the kidney tissue of patients with diabetic nephropathy and compared it with that of patients with other glomerular diseases (minimal change nephrotic syndrome, membranous nephropathy, IgA nephropathy, mesangioproliferative glomerulone-
\end{abstract}

phritis, and lupus nephritis). Expression of P- and Eselectin were both significantly increased in the glomeruli and the interstitium of patients with diabetic nephropathy as compared with those with other glomerular diseases. P- and E-selectin were both expressed along the glomerular capillaries and the peritubular capillaries in the interstitium. Neither P- nor E-selectin were correlated with the number of infiltrated leukocytes in the glomeruli, however, interestingly the E-selectin expression on peritubular capillaries was correlated with the number of infiltrated CD14 positive cells in the interstitium. These results suggest that E-selectin may play a key role in leukocyte infiltration into the renal interstitium in patients with diabetic nephropathy. [Diabetologia (1998) 41: 185-192]

Keywords P-selectin, E-selectin, diabetic nephropathy, advanced glycation endproducts, macrophage.
The infiltration of leukocytes, mainly composed of monocytes/macrophages, into the glomeruli and the interstitium is one of the characteristic findings in renal tissues of diabetic nephropathy [1]. Monocytes/ macrophages, which infiltrate the glomeruli and in-

Received: 22 April 1997 and in final revised form: 29 September 1997

Corresponding author: Dr. K. Hirata, Department of Medicine III, Okayama University Medical School, 2-5-1 Shikata cho, Okayama 700, Japan

Abbreviations: MCNS, Minimal change nephrotic syndrome; MN, membranous nephropathy; MPGN, membranoproliferative glomerulonephritis; SLE, systemic lupus erythematosis; AGE, advanced glycation endproducts; ICAM-1, intercellular adhesion molecule-1; GP IIb/IIIa, glycoprotein IIb/IIIa. terstitium, are considered to play an important role in the progression of glomerulosclerosis [2, 3]. van Goor et al. [4] reported that the depletion of macrophages prevented the progression of glomerulosclerosis in rats after renal ablation. Recently, the analogous pathologic mechanisms between atherosclerosis and glomerulosclerosis $[5,6]$ and the role of macrophages in the progression of atherosclerosis were reported $[7,8]$. The infiltration of leukocytes into inflammatory or atherosclerotic lesions is mediated by adhesion molecules, which are expressed on vascular endothelial cells and leukocytes. However, little is known about the mechanism of leukocyte infiltration into diabetic renal tissues.

Selectins are leukocyte adhesion molecules, which mediate leukocyte infiltration into the inflammatory lesions. The selectin family is composed of three 
Table 1. Clinical characteristics of patients

\begin{tabular}{lcllllll}
\hline Diagnosis & $\begin{array}{l}\text { Number } \\
\text { of cases }\end{array}$ & $\begin{array}{l}\text { Age } \\
(\text { years })\end{array}$ & $\begin{array}{l}\text { Urinary protein } \\
(\mathrm{g} / \text { day })\end{array}$ & $\begin{array}{l}\text { Serum albumin } \\
(\mathrm{g} / \mathrm{l})\end{array}$ & $\begin{array}{l}\mathrm{BUN} \\
(\mathrm{mmol} / \mathrm{l})\end{array}$ & $\begin{array}{l}\mathrm{Cr} \\
(\mu \mathrm{mol} / \mathrm{l})\end{array}$ & $\begin{array}{l}\mathrm{CCr} \\
(\mathrm{ml} / \mathrm{s})\end{array}$ \\
\hline $\begin{array}{l}\text { Normal } \\
\text { Diabetic nephro- } \\
\text { pathy }\end{array}$ & 5 & $42.0(35-65)$ & $0.05(0.0-0.1)$ & $35.5(30.5-40.2)$ & $5.43(2.86-8.21)$ & $94.3(46.3-106.8)$ & $5730(4200-7320)$ \\
MCNS & 7 & $62.9(43-79)$ & $2.28(0.3-4.6)$ & $33.9(22.6-41.3)$ & $9.00(3.57-17.6)$ & $178.9(47.2-445.0)$ & $3132(138-5694)$ \\
$\begin{array}{l}\text { Membranous } \\
\text { nephropathy }\end{array}$ & 5 & $23.0(10-46)$ & $6.74(2.93-27.1)$ & $21.0(11.0-41.5)$ & $8.32(3.53-17.6)$ & $89.0(62.3-130.8)$ & $3198(2328-4710)$ \\
$\begin{array}{l}\text { IgA nephropathy } \\
\text { MPGN }\end{array}$ & 12 & $55.3(47-63)$ & $3.44(2.49-4.0)$ & $23.1(18.3-27.8)$ & $4.57(4.05-5.29)$ & $79.2(78.3-80.1)$ & $6258(4602-8700)$ \\
Lupus nephritis & 12 & $28.2(15-61)$ & $2.00(0.13-6.3)$ & $36.9(24.0-45.5)$ & $5.50(2.86-7.89)$ & $95.2(55.2-154.0)$ & $3624(1380-7740)$ \\
\hline
\end{tabular}

Data are means (range)

MCNS, Minimal change nephrotic syndrome; MPGN, membranoproliferative glomerulonephritis; BUN, blood urea nitrogen; $\mathrm{Cr}$, creatinine; $\mathrm{CCr}$, creatinine clearance

molecules named P-, E- and L-selectin [9]. E-selectin is expressed on endothelium and contributes to monocyte adhesion to endothelium $[10,11]$. E-selectin is expressed on the endothelium at the site of atherosclerosis $[12,13]$ and the serum levels of soluble E-selectin are elevated in patients with hyperlipidaemia [14] and diabetes mellitus [15-17]. On the other hand, P-selectin that is expressed on endothelium or released from platelets contributes to neutrophils or monocytes rolling on the endothelium $[18,19]$. Recently, up-regulation of P-selectin in arteries, veins, and capillaries of choroid has been reported in patients with diabetes [20].

In glomerular diseases, damage to endothelial cells induces release of chemoattractants, adhesion between circulating leukocytes and endothelium, and migration of leukocytes into the kidney tissues [21$23]$. The role of the adhesion molecules in glomerulonephritis has been reported [24-26] and also the management of blocking the leukocyte-endothelium adhesion mechanism to prevent the progression of glomerulonephritis [27, 28]. However, there is little information about the role of selectin molecules in patients with glomerular diseases, especially those with diabetic nephropathy. In the present study, in order to clarify the mechanism of leukocyte infiltration into the glomeruli and the interstitium in diabetic nephropathy, we examined the expression of P-selectin and of E-selectin in the renal tissues of patients with diabetic nephropathy and glomerulonephritis. Moreover we also evaluated the expression of intercellular adhesion molecule-1 (ICAM-1), glycoprotein $\mathrm{IIb} / \mathrm{IIIa}$ (GP IIb/IIIa) as a marker for platelets, CD14 as markers of macrophages and CD11a as markers of leukocytes in these renal tissues.

\section{Subjects and methods}

A total of 51 Japanese patients were studied (25 males and 26 females aged 10 to 79 , mean 40.9 years) (Table 1 ). All underwent percutaneous renal biopsy. Diagnoses were: diabetic nephropathy (7), minimal change nephrotic syndrome (MCNS) (5), membranous nephropathy (MN) (7), IgA nephropathy (12), membranoproliferative glomerulonephritis (MPGN) (3), and lupus nephritis (12). Five normal control subjects were studied. We performed the biopsy for the diabetic patients with proteinuria to examine whether they have other glomerular diseases or not, and we selected the seven cases with only diabetic nephropathy in this study. All the cases had non-insulin-dependent diabetes (NIDDM) with diabetic retinopathy.

Biopsy specimens were routinely stained with haematoxylin-eosin (HE), periodic acid-Schiff (PAS), periodic acid-methenamine (PAM), and Masson stains, and stained against human IgG, IgA, IgM, C3, C1 q, and fibrinogen by immunofluorescence (Cappel, Durham, N. C., USA). Electron microscopic studies were also performed.

Primary antibodies. We used mouse monoclonal antibody (mAb) against human P-selectin (Throm/6(c2); Monsan, Uden, Netherlands), mouse mAb against human E-selectin (C126CI0B7; Bender Medical Systems, Heidelberg, Germany), mouse mAb against human ICAM-1 (6.5B5; DAKO, Glostrup, Denmark), mouse mAb against human GP IIb/IIIa (5B12. DAKO), mouse mAb against CD14 (RPA-M1; Zymed, San Francisco, Calif., USA), and mouse mAb against human CD11a (MHM24, DAKO).

Immunoperoxidase staining. Immunohistochemical staining was carried out as described previously [29]. Kidney tissue specimens were snap frozen in OCT-compound and cut in 4$\mu \mathrm{m}$ thick sections at $-20^{\circ} \mathrm{C}$. The slides on which these sections were mounted were air dried and fixed in cold acetone for $10 \mathrm{~min}$. They were incubated for $20 \mathrm{~min}$ in normal horse serum (Vectastain elite ABC kit; Vector Laboratories, Burlingame, Calif., USA) with avidin blocking (Vector), then incubated for $1 \mathrm{~h}$ in primary antibody with biotin blocking agent (Vector). The incubation time with secondary biotinylated horse anti-mouse $\mathrm{IgG}$ antibody (Vectastain elite $\mathrm{ABC}$ kit) and peroxidase-avidin complex substrates (Vectastain elite ABC kit) was each $30 \mathrm{~min}$. Between the incubations with secondary antibody and that with peroxidase-avidin complex substrates, peroxidase blocking with methanol and $0.3 \% \mathrm{H}_{2} \mathrm{O}_{2}$ was carried 

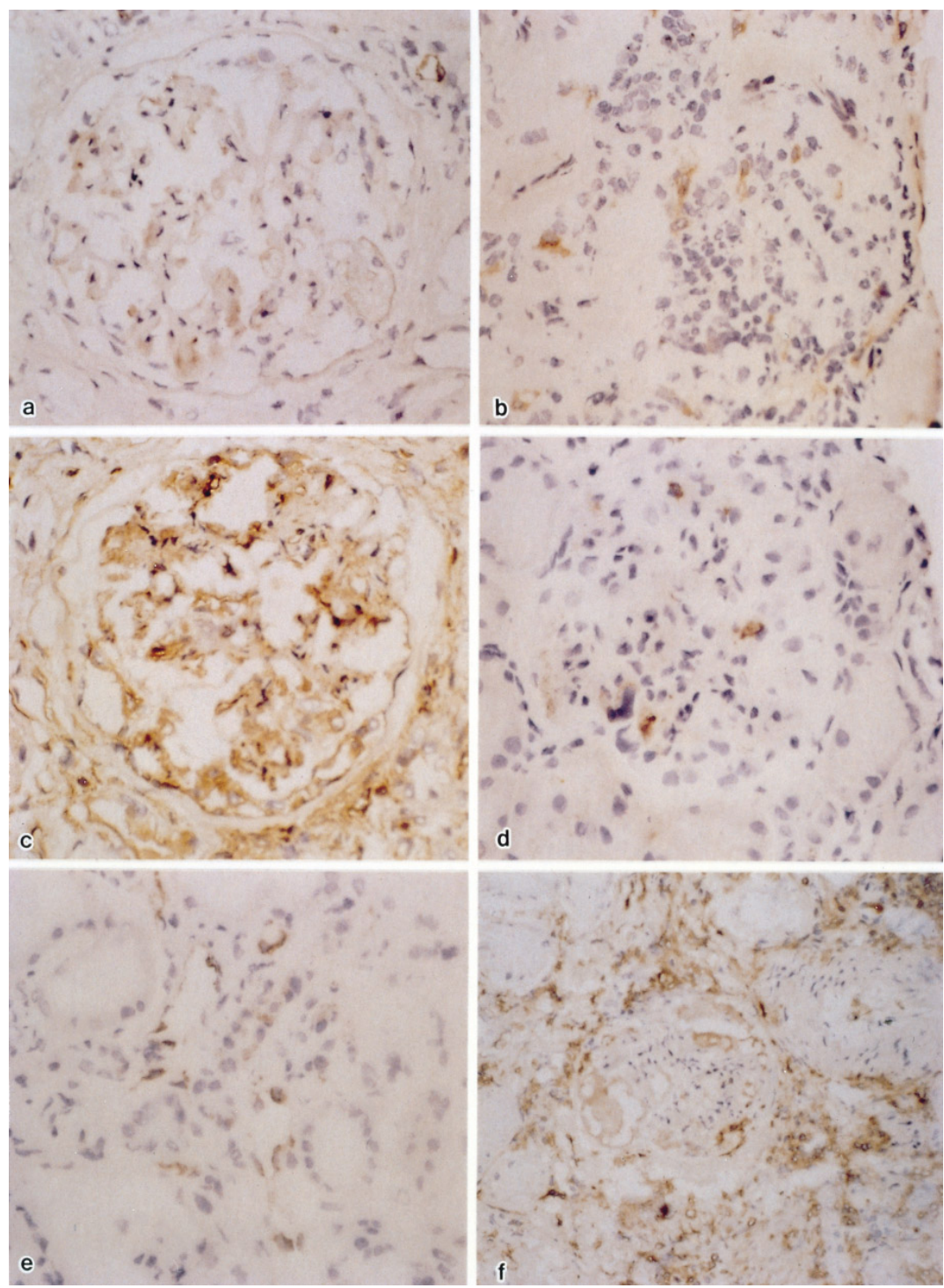

Fig.1a-f. Immunoperoxidase staining for adhesion molecules and marker of leukocytes in diabetic nephropathy. P-selectin (a) and E-selectin (b) in the glomeruli were stained along capillaries of the glomeruli. ICAM-1 was visible in the mesangial area and capillaries in the glomeruli (c). Glycoprotein IIb/IIIa was visible in the lumina of capillaries in the glomeruli (d). Both selectins were observed at peritubular capillaries in the interstitium.(P-selectin staining, e) CD14-positive cells were visible in the glomeruli and the interstitium (f)

out for $30 \mathrm{~min}$. All incubations at room temperature were followed by two washings in phosphate buffered saline, $\mathrm{pH}$ 7.2, for $10 \mathrm{~min}$ each. The sections, in Tris buffer, $\mathrm{pH}$ 7.6, were exposed to diaminobenzidine and $\mathrm{H}_{2} \mathrm{O}_{2}$ for 7 min. Slides were counterstained with Mayer's-haematoxylin and dehydrated in a graded series of ethanol and xylene, then mounted in a xylene-based medium.

Statistical analysis. We semiquantitatively evaluated the intensity of staining of P-selectin, E-selectin, GP IIb/IIIa, ICAM-1 in the glomeruli as follows: $0,1+, 2+, 3+, 4+[30]$.

- $0=$ no staining of the glomerular tuft.

- $1=$ staining of 1 to $25 \%$ of the glomerular tuft.

- 2 = staining of 25 to $50 \%$ of the glomerular tuft.

- 3 = staining of 50 to $75 \%$ of the glomerular tuft and showing focally increased staining.

- 4 = strong staining of more than $75 \%$ of the glomerular tuft.

We counted the number of CD14 or CD11a positive cells in the glomeruli. In the interstitium, we evaluated the number of positive peritubular capillaries for P-selectin or E-selectin, the number of positive cells for CD14 or CD11a, the number of positive lumens of GP IIb/IIIa.

In addition, we evaluated the degree of diabetic nephropathy. The degree of glomerulosclerosis was graded $0-4$ according to Gellman et al. [31], and the degree of interstitial fibrosis was graded 0-3: $0=$ no fibrosis, $1=$ mild, $2=$ moderate, $3=$ severe.

Statistical significance (defined as $p<0.05$ ) was evaluated by using Spearman's correlation coefficient between each staining marker and the clinical data in diabetic nephropathy and was evaluated by using the Kruskal-Wallis test between each disease. 

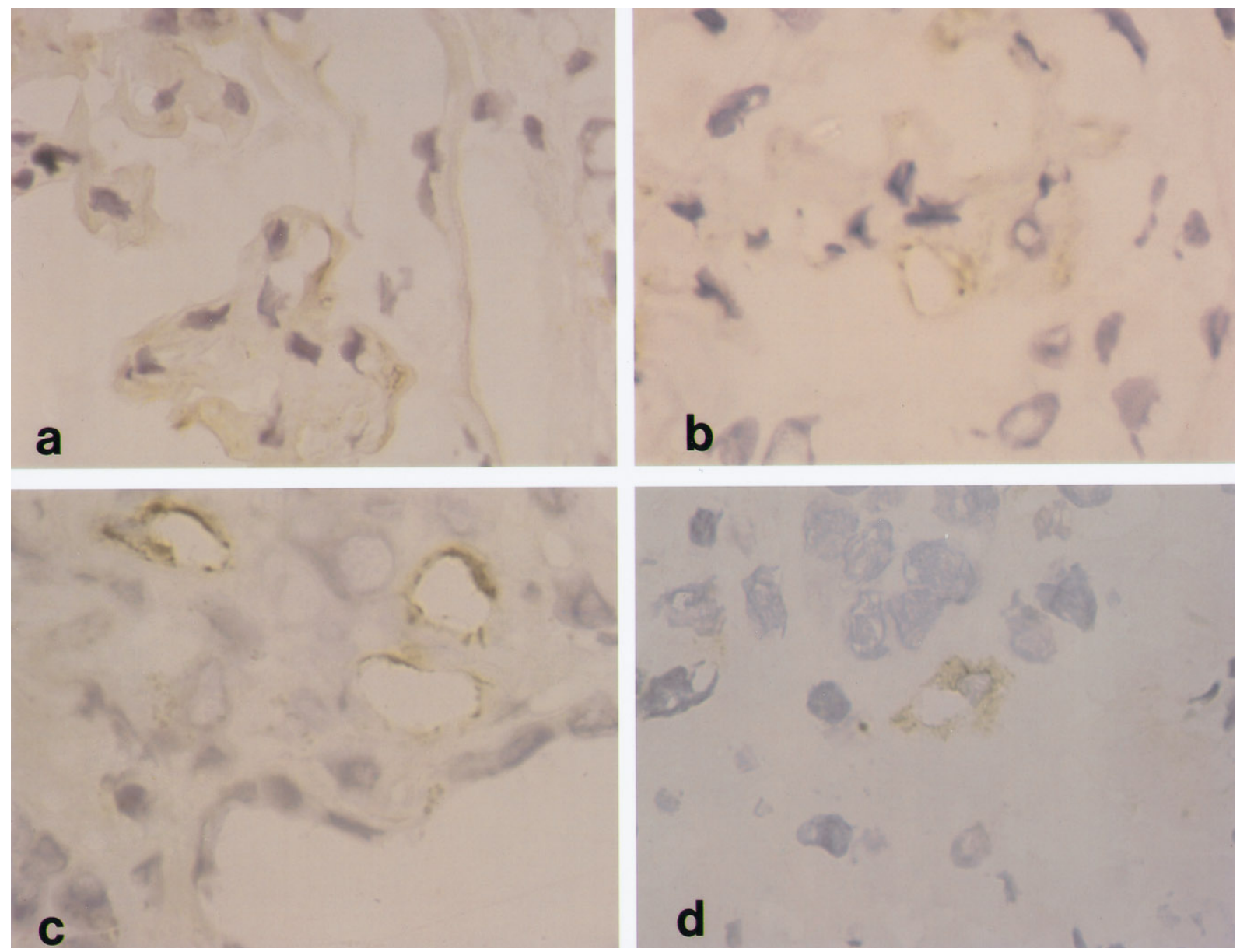

Fig. 2a-d. Enlarged photomicrographs of immunoperoxidase stain for P- and E-selectin. Staining for P-selectin on endothelium of capillary in the glomerulus (a), E-selectin on endothelium of capillary in the glomerulus (b), P-selectin on endothelium of peritubular capillary in the interstitium (c), and E-selectin on endothelium of peritubular capillary in the interstitium (d). These photographs are high magnification

\section{Results}

Normal kidneys. Neither P-selectin nor E-selectin was detected in the glomeruli or the interstitium. ICAM-1 was observed along the capillaries of the glomeruli and the vascular endothelium of peritubular capillaries in the interstitium. Expression of GP $\mathrm{IIb} / \mathrm{III}$ a was evident in the lumina of capillaries in a few glomeruli and of vessels in the interstitium. Some cells that expressed CD14 and CD11a were identified in the glomeruli and also scattered through the interstitium.

Diabetic nephropathy. Staining for P-selectin and Eselectin were observed in diabetic nephropathy (Fig. $1 \mathrm{a}, \mathrm{b}$ and e). P-selectin and E-selectin were both evident in the endothelial cells of capillaries in the glomeruli (Fig. $2 \mathrm{a}$ and $\mathrm{b}$ ) and those of peritubular cap-

illaries of the interstitium (Fig. 2c and d). GP IIb/IIIa was present in the lumina of glomerular capillaries and peritubular capillaries (Fig. 1 d). However, the distribution of GP IIb/IIIa was not correlated with that of P-selectin and E-selectin. CD14 positive cells were increased in the glomeruli and the interstitium (Fig.1f).

We assessed the correlation between the clinical data, the degree of diabetic nephropathy, and the expression of selectins in seven cases of NIDDM (Table 2). The correlation between urinary protein and sclerosis grade $(r=0.854)$, urinary protein and interstitial fibrosis $(r=0.905)$, sclerosis grade and interstitial fibrosis $(r=0.917)$ was significant $(p<0.05)$, but there was no correlation between glycated haemoglobin and other clinical data, between the grading of $\mathrm{P}$ or E-selectin and other clinical data including glycated haemoglobin.

On the other hand, the correlation between each staining marker in the glomeruli and those in the interstitium are represented in Table 3. In the glomeruli, expression of selectins was not correlated with the number of CD14 or CD11 a positive cells (Table 3 ). In the interstitium, E-selectin positive vessels were correlated with the number of CD14 positive cells and CD11 a positive cells, although P-selectin positive vessels were not correlated with the infiltrated leukocytes (Table 3 ). 
Table 2. Clinical features and expression of $\mathrm{P}$ - and E-selectin in diabetic patients

\begin{tabular}{|c|c|c|c|c|c|c|c|c|c|c|c|}
\hline \multirow[t]{2}{*}{$\overline{\text { Sex }}$} & \multirow{2}{*}{$\begin{array}{l}\text { Age } \\
\text { (years) }\end{array}$} & \multirow{2}{*}{$\begin{array}{l}\text { Urinary } \\
\text { protein } \\
\text { (g/day) }\end{array}$} & \multirow{2}{*}{$\begin{array}{l}\mathrm{CCr} \\
(\mathrm{ml} / \mathrm{s})\end{array}$} & \multirow{2}{*}{$\begin{array}{l}\mathrm{HbA}_{1 \mathrm{c}} \\
(\%)\end{array}$} & \multirow{2}{*}{$\begin{array}{l}\text { Cholesterol } \\
(\mathrm{mmol} / \mathrm{l})\end{array}$} & \multirow{2}{*}{$\begin{array}{l}\text { Sclerosis } \\
\text { grade }\end{array}$} & \multirow{2}{*}{$\begin{array}{l}\text { Interstitial } \\
\text { fibrosis }\end{array}$} & \multicolumn{2}{|c|}{ P-selectin } & \multicolumn{2}{|c|}{ E-selectin } \\
\hline & & & & & & & & glom & inter & glom & inter \\
\hline $\bar{M}$ & 65 & 0.3 & 4998 & 8.1 & 3.75 & 1 & 1 & 1 & 5.3 & 1 & 1.2 \\
\hline $\mathrm{M}$ & 43 & 0.6 & 5076 & 4.9 & 3.90 & 1 & 1 & 1 & 5.0 & 1 & 12.0 \\
\hline M & 63 & 2.0 & 1068 & 6.5 & 3.90 & 2 & 1 & 3 & 15.0 & 3 & 15.0 \\
\hline M & 65 & 4.25 & 3720 & 6.2 & 4.71 & 2 & 2 & 3 & 8.1 & 2 & 6.3 \\
\hline M & 79 & 3.1 & 1218 & 5.0 & 6.67 & 3 & 2 & 1 & 15.0 & 1 & 5.6 \\
\hline
\end{tabular}

glom, Glomerulus; inter, interstitium

In the glomeruli, the intensity of staining with $\mathrm{P}$ - or E-selectin was represented as 0 to 4 grades; in the interstitium, the inten-

Table 3. Correlation coefficient between each staining marker in diabetic nephropathy

\begin{tabular}{lcrrrl}
\hline Glomeruli & P-selectin & E-selectin & ICAM-1 & GP IIb/IIIa & CD14 \\
\hline P-selectin & 1 & & & & \\
E-selectin & $0.887^{\mathrm{a}}$ & 1 & & & \\
ICAM-1 & -0.569 & -0.642 & 1 & & \\
GP IIb/IIIa & 0.353 & 0.497 & -0.655 & 1 & \\
CD14 & 0.193 & 0.305 & 0.208 & -0.564 & 1 \\
CD11a & 0.141 & 0.198 & 0.000 & -0.239 & 0.679 \\
\hline
\end{tabular}

Interstitium P-selectin E-selectin ICAM-1 GP IIb/IIIa CD14

\begin{tabular}{lrrrrl}
\hline P-selectin & \multicolumn{1}{l}{1} & & & & \\
E-selectin & 0.360 & 1 & & & \\
ICAM-1 & 0.080 & 0.158 & 1 & & \\
GP IIb/IIIa & -0.378 & -0.143 & -0.158 & 1 & \\
CD14 & 0.280 & $0.927^{\mathrm{b}}$ & 0.000 & -0.111 & 1 \\
CD11a & 0.306 & $0.857^{\mathrm{a}}$ & -0.158 & -0.143 & $0.927^{\mathrm{a}}$ \\
\hline
\end{tabular}

${ }^{\mathrm{a}} p<0.05 ;{ }^{\mathrm{b}} p<0.01$

Primary glomerulonephritis. Except in a few cases of IgA nephropathy, the glomeruli were not stained for P-selectin or E-selectin (Fig. $3 \mathrm{a}$ and b). In the interstitium, P-selectin and E-selectin were stained along the peritubular capillaries. However, ICAM-1 was stained along the capillaries of the glomeruli and vessels of the interstitium.

Lupus nephritis. Expression of P-selectin and E-selectin was observed in some cases of lupus nephritis. We recognized P-selectin and E-selectin along the endothelial side of capillaries of the glomeruli and peritubular capillaries of the tubular interstitium (Fig. $4 \mathrm{a}$ and b). CD14 and CD11a positive cells were increased in the glomeruli and the interstitium.

Expression of $P$ - and E-selectin in several types of glomerular disease. The $\mathrm{P}$ - and E-selectin scores in glomerular disease are summarized in Table 4. We represented the intensity of staining as mean \pm SEM/ one glomerulus in the glomeruli or mean \pm SEM/ $\mathrm{mm}^{2}$ in the interstitium. In the patients with diabetic nephropathy, P- and E-selectin expression was significantly increased compared to that in the patients sity of staining with P- or E-selectin was represented as numbers of positive peritubular capillaries $/ \mathrm{mm}^{2}$

with other glomerular diseases, except E-selectin expression in the glomeruli compared to that in patients with lupus nephritis.

\section{Discussion}

The present study investigated expression of $\mathrm{P}$ - and E-selectin in kidney specimens obtained from patients with NIDDM, as compared to those from patients with other primary or secondary glomerular diseases. Interestingly, the grade of selectin expression in diabetic nephropathy was significantly higher than that in normal control subjects and in other glomerular diseases, including lupus nephritis and MPGN, in which infiltration of numerous macrophages was observed in the glomeruli (Table 4). A previous study reported that $\mathrm{P}$ - and E-selectin is expressed on extraglomerular vascular endothelium in human glomerulonephritis [32]. Pall et al. [33] reported that E-selectin is expressed in the glomeruli of patients with diabetic nephropathy and severe pyelonephritis. Cominacini et al. [17] reported that the increased level of plasma soluble E-selectin is found and correlated with glycated haemoglobin in the patients with diabetes. On the other hand, Steiner et al. [15] reported that the serum level of E-selectin is independent of glycaemic control. In our study, no relationship between the glycaemic control, urinary protein or other clinical data and the grade of selectin expression was found. However, the number of infiltrated CD14 positive cells into the interstitium was correlated with the intensity of E-selectin on peritubular capillaries in the interstitium.

$\mathrm{P}$-selectin is known to be found both in endothelial cells and in platelets. In our study, P-selectin is considered to be expressed on the endothelial cell surface because the distribution of P-selectin was not correlated with that of GP IIb/IIIa.

Concerning the mechanism of elevated expression of P- and E-selectin, Kim et al. [34] reported that a high glucose concentration did not induce expression of selectin molecules on human aortic endothelial 


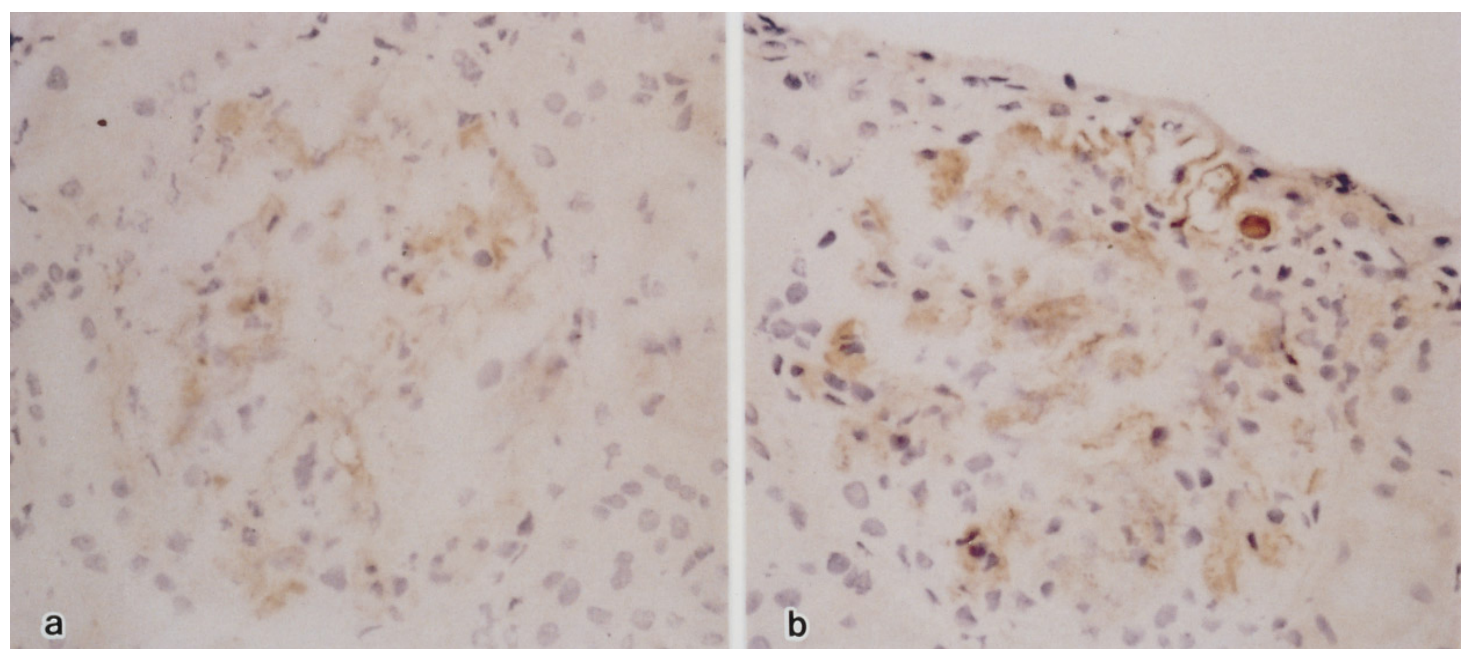

Fig. 3 a, b. Immunoperoxidase staining for P-selectin (a) and E-selectin (b) in the glomeruli in MCNS. There was no staining in the glomeruli

cells. In our preliminary experiments, a high glucose concentration did not induce expression of P- and Eselectin on human umbilical vein endothelial cells, as detected by immunofluorescence (data not shown). Thus, there is no evidence that a high glucose concentration can induce selectin expression. Richardson et al. [35] reported the possibility that elevation of LDL-cholesterol and triglyceride accelerates expression of selectin on aortic endothelium. This mechanism was not confirmed in our study, because selectin was not expressed in the glomeruli of patients with nephrotic syndrome in whom severe hyperlipidaemia was present. It was recently demonstrated that advanced glycation endproducts (AGE) accumulate in

Fig. 4 a, b. Immunoperoxidase staining for P-selectin (a) and E-selectin (b) in the glomeruli in lupus nephritis. Both P-selectin and E-selectin were observed along capillaries in the glomeruli diabetic kidney tissues. Mitsuhashi et al. [36] reported that AGE content in the renal cortex of streptozotocin-induced diabetic rats is increased, as compared with normal controls [36]. Miyata et al. [37] demonstrated that pyrraline is detected in the glomeruli of patients with diabetic nephropathy. We also demonstrated that AGE accumulates in the glomeruli and the tubuli of patients with diabetic nephropathy and of streptozotocin-induced diabetic rats [29, 38]. AGE is known to stimulate the production of tumour-necrotizing factor- $\alpha$ (TNF- $\alpha$ ) and interleukin-1 (IL-1) via the AGE receptor [39]. Schmidt et al. [40] reported that AGE induce expression of vascular cell adhesion molecule-1 (VCAM-1) on human endothelial cells. AGE receptor is expressed on macrophages, vascular endothelial cells, and glomerular mesangial cells [41]. Because expression of P- and Eselectins is induced by inflammatory cytokines, such as TNF-a and IL-1, [42] expression of selectins may be enhanced by AGE that accumulate in the kidney in diabetic nephropathy.

Concerning the role of macrophages in diabetic nephropathy, Furuta et al. [1] reported that glomerular macrophages, but not lymphocytes, are involved in the progression of glomerular sclerosis. As for interstitial lesions, several reports have been published that tubulo-interstitial change is an important factor

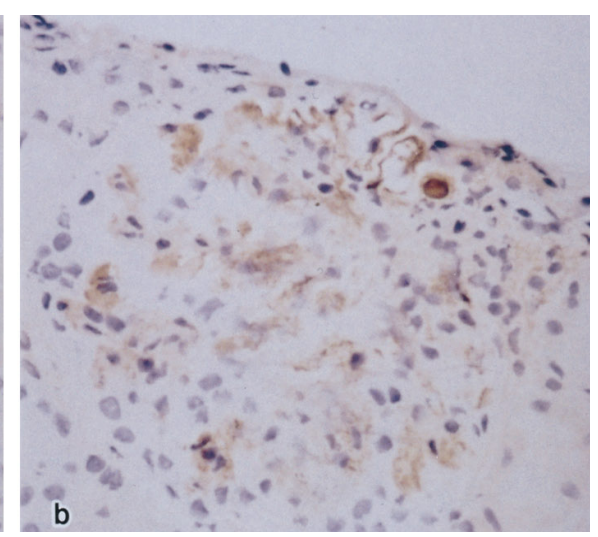


Table 4. Expression of P-selectin and E-selectin in various types of glomerular diseases

\begin{tabular}{|c|c|c|c|c|}
\hline \multirow[t]{2}{*}{ Diagnosis } & \multicolumn{2}{|l|}{ P-selectin } & \multicolumn{2}{|l|}{ E-selectin } \\
\hline & glomerulus & interstitium & glomerulus & interstitium \\
\hline Normal & $0 \pm 0$ & $0 \pm 0$ & $0 \pm 0$ & $0 \pm 0$ \\
\hline MCNS & $0 \pm 0$ & $0 \pm 0$ & $0 \pm 0$ & $0 \pm 0$ \\
\hline Membranous nephropathy & $0 \pm 0$ & $0 \pm 0$ & $0 \pm 0$ & $0 \pm 0$ \\
\hline IgA nephropathy & $0.06 \pm 0.06$ & $1.09 \pm 0.51$ & $0.50 \pm 0.38$ & $4.53 \pm 2.51$ \\
\hline MPGN & $0 \pm 0$ & $1.00 \pm 0.89$ & $0 \pm 0$ & $0.63 \pm 0.44$ \\
\hline
\end{tabular}

Data are

${ }^{\mathrm{a}} p<0.05$ vs normal; ${ }^{\mathrm{b}} p<0.05$ vs MCNS; ${ }^{\mathrm{c}} p<0.05$ vs membranous nephropathy; ${ }^{\mathrm{d}} p<0.05$ vs $\mathrm{IgA}$ nephropathy; ${ }^{\mathrm{e}} p<0.05$ vs MPGN; ${ }^{\mathrm{f}} p<0.05$ vs lupus nephritis

in the progression of diabetic nephropathy [43-45]. Bohle et al. [46] reported that macrophages and Tlymphocytes play important roles in tubulo-interstitial damage in diabetic nephropathy. In our study, macrophage infiltration was correlated with E-selectin positive endothelium in the renal interstitium. Thus, E-selectin supposedly mediates the infiltration of macrophages into the kidney interstitium. However, it remains unclear whether selectins actually participate in macrophage infiltration into the glomeruli, because there was no correlation between expression of selectins and the degree of infiltration of macrophages in the glomeruli.

The present study showed that P- and E-selectin were up-regulated in the renal tissue of patients with diabetic nephropathy. Especially, E-selectin may be important to tubulo-interstitial injury by promoting the infiltration of macrophages into the renal interstitium.

Acknowledgements. This study was supported by a Grant-in Aid for Scientific Research from the Ministry of Education, Science and Culture of Japan.

\section{References}

1. Furuta T, Saito T, Ootaka T, et al. (1993) The role of macrophages in diabetic glomerulosclerosis. Am J Kidney Dis 21: 480-485

2. Magil AB, Cohen AH (1989) Monocytes and focal glomerulosclerosis. Lab Invest 61: 404-409

3. Saito T, Ootaka T, Sato H, et al. (1993) Participation of macrophages in segmental endocapillary proliferation preceding focal glomerular sclerosis. J Pathol 170: 179-185

4. van Goor H, van der Horst MLC, Fidler V, Grond J (1992) Glomerular macrophage modulation affects mesangial expansion in the rat after renal ablation. Lab Invest 66: 564571

5. Diamond JR (1991) Analogous pathobiologic mechanisms in glomerulosclerosis and atherosclerosis. Kidney Int [Suppl] 31: S29-S34

6. Baba N, Shimokama T, Watanabe T (1993) Effects of hypercholesterolemia on initial and chronic phases of rat nephrotoxic serum nephritis: development of focal segmental glomerulosclerosis, analogous to atherosclero- sis. Virchows Arch B Cell Pathol Incl Mol Pathol 64: 97-105

7. Brown MS, Ho YK, Goldstein JL (1980) The cholesteryl ester cycle in macrophage foam cells: continual hydrolysis and re-esterification of cytoplasmic cholesteryl esters. J Biol Chem 255: 9344-9352

8. Rothblat G, Phillips MC (1991) Cholesterol efflux from arterial wall cells. Atherosclerosis 2: 288-294

9. Bevilacqua M, Butcher E, Furie B, et al. (1991) Selectins: a family of adhesion receptors. Cell 67: 233

10. Bevilacqua MP, Pober JS, Mendrick DL, Cotran RS, Gimbrone MAJr (1987) Identification of an inducible endothelial-leukocyte adhesion molecule. Proc Natl Acad Sci USA 84: 9238-9242

11. Fries JWU, Williams AJ, Atkins RC, Newman W, Lipscomb MF, Collins T (1993) Expression of VCAM-1 and E-selectin in an in vivo model of endothelial activation. Am J Pathol 143: 725-737

12. Davies MJ, Gordon JL, Gearing AJH, et al. (1993) The expression of the adhesion molecules ICAM-1, VCAM-1, PECAM, and E-selectin in human atherosclerosis. J Pathol 171: 223-229

13. van del Wal AC, Das PK, Tigges AJ, Becker AE (1992) Adhesion molecules on the endothelium and mononuclear cells in human atherosclerotic lesions. Am J Pathol 141: 1427-1433

14. Hackman A, Abe Y, Insall W Jr, et al. (1996) Levels of soluble cell adhesion molecules in patients with dyslipidemia. Circulation 93: 1334-1338

15. Steiner M, Reinhardt KM, Krammer B, Ernst B, Blann AD (1994) Increased levels of soluble adhesion molecules in type 2 (non-insulin dependent) diabetes mellitus are independent of glycaemic control. Thromb Haemost 72: 979984

16. Gearing AJH, Hemingway I, Pigott R, Hughes J, Rees AJ, Cashman SJ (1992) Soluble forms of vascular adhesion molecules, E-selectin, ICAM-1 and VCAM-1: pathological significance. Annals NY Acad Sci 667: 324-331

17. Cominacini L, Pasini AF, Garbin U, et al. (1995) Elevated levels of soluble E-selectin in patients with IDDM and NIDDM: relation to metabolic control. Diabetologia 38: 1122-1124

18. Bonfanti R, Furie BC, Furie B, Wagner DD (1989) PADGEM (GMP-140) is a component of Weibel-Palade bodies of human endothelial cells. Blood 73: 1109-1112

19. Larsen E, Celi A, Gilbert GE, et al. (1989) PADGEM protein: a receptor that mediates the interaction of activated platelets with neutrophils and monocytes. Cell 59: 305-312

20. McLeod DS, Lefer DJ, Merges C, Lutty GA (1995) Enhanced expression of intercellular adhesion molecule-1 
and $\mathrm{P}$-selectin in the diabetic human retina and choroid. Am J Pathol 147: 642-653

21. Brady HR (1994) Leukocyte adhesion molecules and kidney diseases. Kidney Int 45: 1285-1300

22. Bruijn JA, de Heer E (1995) Biology of disease. Adhesion molecules in renal diseases. Lab Invest 72: 387-394

23. Furie MB, Randolph GJ (1995) Chemokines and tissue injury. Am J Pathol 146: 1287-1301

24. Kawasaki K, Yaoita E, Yamamoto T, Tamatani T, Miyasaka M, Kihara I (1993) Antibodies against intercellular adhesion molecule-1 and lymphocyte function-associated antigen-1 prevent glomerular injury in rat experimental crescentic glomerulonephritis. J Immunol 150: 1074-1083

25. Lhotta K, Neumayer HP, Joannidis M, Geissler D, König P (1991) Renal expression of intercellular adhesion molecule-1 in different forms of glomerulonephritis. Clin Science 81: 477-481

26. Chow J, Hartley RB, Jagger C, Dilly SA (1992) ICAM-1 expression in renal disease. J Clin Pathol 45: 880-884

27. Nishikawa K, Guo Y-J, Miyasaka M, et al. (1993) Antibodies to intercellular adhesion molecule-1/lymphocyte function-associated antigen-1 prevent crescent formation in rat autoimmune glomerulonephritis. J Exp Med 177: 667-677

28. Harning R, Pelletier J, Van G, Takei F, Merluzzi VJ (1992) Monoclonal antibody to MALA-2 (ICAM-1) reduces acute autoimmune nephritis in kdkd mice. Clin Immunol Immunopathol 64: 129-134

29. Makino H, Shikata K, Hironaka K, et al. (1995) Ultrastructure of nonenzymatically glycated mesangial matrix in diabetic nephropathy. Kidney Int 48: 517-526

30. Floege J, Burns MW, Alpers CE, et al. (1992) Glomerular cell proliferation and PDGF expression precede glomerulosclerosis in the remnant kidney model. Kidney Int 41: 297-309

31. Gellman DD, Pirani CL, Soothill JF, Muehrecke RC, Kark RM (1959) Diabetic nephropathy: a clinical and pathologic study based on renal biopsies. Medicine 38: 321-367

32. Roy-Chaudhury P, Wu B, King G, et al. (1996) Adhesion molecule interactions in human glomerulonephritis: importance of the tubulointerstitium. Kidney Int 49: 127-134

33. Pall AA, Garner CM, Richards GM, et al. (1993) Expression of E-selectin in the human kidney. Nephrol Dial Transplant 8: 1429-1430

34. Kim JA, Berliner JA, Natarajan RD, Nadler JL (1994) Evidence that glucose increases monocyte binding to human aortic endothelial cells. Diabetes 43: 1103-1107

35. Richardson M, Hadcock SJ, DeReske M, Cybulsky MI (1994) Increased expression in vivo of VCAM-1 and E-selectin by the aortic endothelium of normolipemic and hy- perlipemic diabetic rabbits. Arterioscler Thromb 14: 760769

36. Mitsuhashi T, Nakayama H, Itoh T, et al. (1993) Immunochemical detection of advanced glycation end products in renal cortex from STZ-induced diabetic rat. Diabetes 42: 826-832

37. Miyata S, Monnier V (1992) Immunohistochemical detection of advanced glycosylation end products in diabetic tissues using monoclonal antibody to pyrraline. J Clin Invest 89: 1102-1112

38. Shikata K, Makino H, Sugimoto M, et al. (1995) Localization of advanced glycation endproducts in the kidney of experimental diabetic rats. J Diab Compl 9: 269-271

39. Vlassara H, Bucala R, Striker L (1994) Biology of disease: pathogenic effects of advanced glycosylation: biochemical, biologic, and clinical implications for diabetes and aging. Lab Invest 70: 138-151

40. Schmidt AM, Hori O, Chen JX, et al. (1995) Advanced glycation endoproducts interacting with their endothelial receptor induce expression of vascular cell adhesion molecule-1 (VCAM-1) in cultured human endothelial cells and in mice: a potential mechanism for the accelerated vasculopathy of diabetes. J Clin Invest 96: 1395-1403

41. Skolnik EY, Yang Z, Makita Z, Radoff S, Kirstein M, Vlassara H (1991) Human and rat mesangial cell receptors for glucose-modified proteins: Potential role in kidney tissue remodelling and diabetic nephropathy. J Exp Med 174: 931-939

42. Brownlee M, Cerami A, Vlassara H (1988) Advanced glycosylation end products in tissue and the biochemical basis of diabetic complications. N Engl J Med 318: 1315-1321

43. Bader R, Bader H, Grund KE, Mackensen-Haen S, Christ H, Bohle A (1980) Structure and function of the kidney in diabetic glomerulosclerosis: correlations between morphological and functional parameters. Path Res Pract 167: 204-216

44. Mauer SM, Steffes MW, Ellis EN, Sutherland DER, Brown DM, Goetz FC (1984) Structural-functional relationships in diabetic nephropathy. J Clin Invest 74: 1143-1155

45. Suzuki Y, Ueno M, Hayashi H, et al.(1994) A light microscopic study of glomerulosclerosis in Japanese patients with noninsulin-dependent diabetic mellitus: the relationship between clinical and histological features. Clin Nephrol 42: 155-162

46. Bohle A, Wehrmann M, Bogenschütz O, Batz C, Müller CA, Müller GA (1991) The pathogenesis of chronic renal failure in diabetic nephropathy: investigation of 488 cases of diabetic glomerulosclerosis. Path Res Pract 187: 251-259 